\title{
EVALUATION OF THE EFFECTS OF WASTE GLASS IN ASPHALT CONCRETE USING THE MARSHALL TEST
}

\author{
Olumide Moses Ogundipe ${ }^{1^{*}}-$ Emeka Segun Nnochiri $^{2}$
}

\begin{abstract}
${ }^{1}$ Department of Civil Engineering, Faculty of Engineering, Ekiti State University, P.M.B. 5363, Ado-Ekiti, Nigeria ${ }^{2}$ Department of Civil and Environmental Engineering, College of Engineering, Afe Babalola University, Ado-Ekiti, Nigeria
\end{abstract}

\begin{tabular}{l} 
ARTICLE INFO \\
\hline Article history: \\
Received: 23. 2. 2018. \\
Received in revised form: 23. 8. 2018. \\
Accepted: 24. 8. 2018. \\
\hline Keywords: \\
Waste \\
Glass \\
Asphalt concrete \\
Marshall \\
Stability \\
Flow \\
\hline DOI: http://doi.org/10.30765/er.40.2.04
\end{tabular}

\section{Introduction}

Large quantities of waste are generated daily because of domestic, industrial and agricultural activities around the world. The major concern of the authorities has been the safe disposal of these wastes. Major methods of the waste disposal are incineration, landfills, recycling and reuse. In some third world countries, the wastes are disposed in

\begin{abstract}
:
The study investigates the use of waste glass as filler in asphalt concrete. Waste glass constitutes a significant proportion of the waste generated in both developed and developing countries. Successful utilization of the waste glass in asphalt will reduce the problem faced by environmental agencies at ensuring safe disposal of the nonbiodegradable waste and may improve the asphalt properties. In the study, a waste glass in form of a filler was introduced into the asphalt mix at $8 \%$, $10 \%, 12 \%, 14 \%, 16 \%, 18 \%$ and $20 \%$ of the total mix. The asphalt concrete samples with and without waste glass as filler were subjected to the Marshall test to determine the stability, flow, air voids, void in mix aggregate and void filled with bitumen. The Marshall test results show that stability increases when increasing glass filler up to $18 \%$, although the values were lower than of the asphalt concrete without waste glass. This implies improved resistance to fatigue for higher waste glass content. Also, the flow increases with increasing glass filler, which implies the resistance to permanent deformation which did not improve. Generally, the introduction of waste glass in the asphalt concrete is environmentally friendly, and it will aid the sustainable management of waste glass.
\end{abstract}

open sites. Some of these disposal methods pose great treats to human lives and the environment. Therefore, more attention is being focused on recycling and reuse of the waste products. According to Kandhal [1], the hot mix asphalt (HMA) industry was pressured in recent years to incorporate a wide variety of waste materials into HMA pavements. Warren [2] stated that the introduction of waste material into HMA involved

\footnotetext{
${ }^{*}$ Corresponding author. Tel.: +2348107825001

E-mail address: momide2002@yahoo.com
} 
some legitimate concerns like the properties of the HMA incorporating waste materials, the impact on production, recyclability and consistent quality, environmental concerns like the emissions and leaching and economic concerns like price, life cycle cost, disposal cost, salvage value and lack of incentive.

Andela and Sorge [3] defined glass as an inert material with good compressive strength, hardness, compactability, permeability and workability, making it suitable for a wide array of uses. These properties could be employed to improve performance of asphalt concrete, while solving the problem of ensuring safe disposal of the waste glass. They observed that the benefits associated with the use of recycled glass in New York communities include cost savings related to transporting and disposing of glass, lower-cost acceptable replacement for virgin aggregates (primarily sand and stone) in several construction applications, extending the life of an existing quarry and reducing demand for new quarry sites and increasing the useful life of the landfill. As one of the materials, asphalt concrete incorporating glass is usually referred to as glasphalt. Many researchers have reported that waste glass can be introduced into asphalt concrete successfully. Larsen [4] carried out an extensive review of literature on both laboratory and field evaluations of glasphalt since 1969 and reported that glasphalt was successfully mixed and placed in at least 45 locations in the U.S. and Canada between 1969 and 1988, but that the use was restricted to city streets, driveways and parking lots, and not to high-volume, high-speed highways. He identified the problems with glasphalt as: loss of adhesion between asphalt and glass; maintenance of an adequate level of skid resistance, especially with coarse particles; breakage of glass and subsequent ravening under studded tires; lack of adequate and consistent supply of glass; and increased production costs (estimated at $\$ 5 / \mathrm{Mg}$ more than the conventional HMA mix in Connecticut). He concluded that glasphalt should be used only as a base course to alleviate potential skid resistance and surface ravening problems and no more than a maximum of $9.5 \mathrm{~mm}$ glass should be used in glasphalt, with hydrated lime added to prevent stripping. Also, Abu Salem et. al. [5] reported that a large amount of glass waste from industry has been an urgent subject at both national and global levels and that glass recycling can save energy and decrease environmental waste. They stated that nearly 10 million tons of glass wastes were being generated every year around the world. They observed that the high angularity of cullet, compared with rounded sand, could enhance the stability of asphalt mixes, where properly sized cullet is used and could result in low absorption, low specific gravity and low thermal conductivity, which reportedly offer enhanced heat retention in mixes with glass.

Halstead [6] stated that in his review of the use of waste glass in highway construction glass had been used as a component of unbound aggregates for embankments, trench backfills, backfills for walls, pipe bedding, gravel bases, ballast, etc., and in hotmix asphalt base courses and surfaces. He mentioned that, although it is not cost-effective to use waste glass as a replacement for natural fine aggregate in asphalt mixtures, it could be used in many highway construction applications with satisfactory performance. He stated further that its use in highway application would provide a viable alternative to disposal in landfills and the cost of otherwise disposing of it could make it a least costly alternative. Issa [7] investigated the use of waste glass from car windscreen in asphalt concrete using the Marshall test. In his study, glass particles with diameter less than $4.75 \mathrm{~mm}$ were used and nine samples of crushed glass were prepared with $5 \%$, $10 \%$, and $15 \%$ by the weight of total aggregates. His results showed that there was an improvement at $10 \%$ glass especially at low bitumen percentage (less than 5\%) and the average flow of asphalt without glass was higher in comparison with the glass-asphalt. The diameter of the glass particle used in his study was within the range suggested by Larsen, [4].

Arnold et. al. [8] used the repeated load triaxial (RLT) test and associated rut depth modelling to assess the effect of adding various percentages by mass of recycled crushed glass to a basecourse aggregate on the performance/rut resistance. Their aim was to determine the maximum percentage of recycled glass that could be safely added to an aggregate used as a basecourse without impairing its performance. They considered $0 \%, 10 \%, 20 \%, 30 \%$ and $50 \%$ of crushed glass and observed that adding glass in quantities greater than $20 \%$ moved the final grading of the aggregate glass mixture outside the limits of the TNZ M/4 specification. They reported that the performance of the basecourse improved with increasing percentages of crushed glass up to $30 \%$. They concluded that adding crushed glass in quantities of up to $30 \%$ by mass had little or no effect on aggregate rut depth performance. 
Swearingen et. al. [9] investigated the possibility of using the recycled materials for highway construction and reported that waste glass could be used in asphalt concrete for low-speed and lowvolume roads and in asphalt base layers of highvolume highways, bike paths or walkways with some limitations which include the waste glass being clean with $100 \%$ passing the $3 / 8$ in sieve and no more than $7 \%$ passing sieve number 200. A maximum of $15 \%$ by volume of waste glass should be used and introduction of anti-strip additive such as hydrated lime should be done. Furthermore, Abu Salem et. al. [5] studied the performance of asphalt concrete mix with some of fractional fine aggregate substituted with 5\%,10\%, $15 \%$ and $20 \%$ glass materials. They found that the waste broken glass can be used in asphalt concrete with the maximal size of $2.36 \mathrm{~mm}$ and the optimal replacement ratio of $10 \%$ and that the strength index, high temperature stability and water stability met the standards of the asphalt mix design. Lastly, they concluded that the water stability of glasphalt could be improved by introducing hydrated lime or liquid antistripping agent.

Anochie-Boateng and George [10] evaluated asphalt concrete mix that utilizes a sustainable crushed glass as a replacement material of a natural aggregate. The study involved a mix design process of a 9.5 mm nominal maximum wearing course glass asphalt with a design traffic level of 30 million ESALs. They performed laboratory tests on the mix, as well as on the component materials and compared the results with the volumetric design criteria set in the new asphalt mix design method for South Africa. They found that the optimum binder content of the glass asphalt mix was 5.1\%. Using the optimum binder content, the volumetric properties of the glass mix were analysed. They reported that the results of the volumetric analysis of the glass asphalt with OBC met the South African criteria. The results of performance-related tests indicated that the tensile strength and durability properties of the glass asphalt mix were comparable to the reference mix. Jony et. al [11] studied the use of glass powder as an alternative to traditional lime stone powder (Gubraa) and ordinary Portland cement fillers in hot asphalt mixtures. In their study, nine mixtures with three types of fillers (lime stone powder, ordinary Portland cement and glass powder) and three filler contents $(4 \%, 7 \%$ and $10 \%$ by weight of total aggregate) were investigated. They found the optimum glass powder content is $7 \%$ and concluded that using the glass powder as filler with such replacement resulted in asphalt concrete with up to $13 \%$ higher stability, 39\% lower flow and 10\% lower density compared to the mixtures with ordinary Portland cement or lime stone powder. Dalloul [12] also studied the effects of crushed waste glass as coarse sand and filler in the asphalt binder course on the properties of hot mix asphalt using Marshall method. In his study, cleaned and crushed waste glass was added to the asphalt mixture using a gradation of $(0 / 4.75) \mathrm{mm}$. His results showed that the optimum bitumen content (OBC) for the mixture without glass was $5.1 \%$ of the total weight of the asphalt mix. He also found that the optimum percentage of glass that could be used in the binder course is $7.5 \%$ of the weight of the aggregates of the Trabia $(0 / 4.75) \mathrm{mm}$ in the asphalt mix. He concluded that the results of Marshall stability, flow, bulk density and air voids of glasphalt were consistent with the specifications range at the different percentages of glass contents (2.5\% - 15\%), except the flow values at 12.5 and 15 $\%$, which were below the minimum specifications limit. Sadeghnejad et. al. [13] investigated the impact of temperature and stress on the rutting behavior of glasphalt mixtures. They modelled the rutting behavior of the asphalt using the results obtained from repeated load axial test. They reported that the effects of waste glass powder on asphalt mixtures at high temperatures were higher which was able to improve the thermal sensitivity of asphalt mixtures. Also, they stated that the glasphalt models had less deformation in the vertical and horizontal directions due to the high power of waste glass powder to improve the properties of asphalt mixtures They concluded that the waste glass powder improved the performance of asphalt mixtures against permanent deformation significantly. Al-Saeedi and Al-Jameel [14] studied reference mix asphalt and mix asphalt with different percentages of the crushed glass. In the study, they considered glass waste with different percent of replacement from $0 \%$ to $100 \%$ in the forms of filler, fine aggregate and coarse aggregate and reported that the results varied with the form of the waste glass. When waste glass was used in the form of a filler, the stability increased slightly as the percentage of glass content increased up to $10 \%$. Then, the stability decreased sharply by about $49 \%$ as the value of glass increased from $0 \%$ to $100 \%$, while the glass flow decreased with this increment. Also, when used as fine aggregate, flow decreased as the percentage of glass increased. When used as coarse aggregate, that is waste glass cullets passing 
$12.5 \mathrm{~mm}$ sieve and retaining on $4.75 \mathrm{~mm}$ sieve, the stability increased by $4.6 \%, 10 \%, 22 \%$ for $10 \%$, $25 \%$ and $50 \%$ replacement, respectively, while it decreased when the cullet was $75 \%$ and $100 \%$ of the virgin aggregates. Generally, they concluded the results showed good indication, especially when using $10 \%$ of the crushed glass instead of coarse aggregate with 40-50 asphalt grades.

Furthermore, Airey et. al. [15] used two asphalt mixture types (gradations) to investigate the performance of glass cullet and slag (BOS and BFS) secondary aggregates in modified bituminous mixtures. They considered $28 \mathrm{~mm}$ dense base asphalt mixture (DBM) as specified in BS 49871:2001 using a 50 penetration grade bitumen and 14 mm stone mastic asphalt (SMA) wearing course asphalt mixture as specified in prEN 131018$5: 2000$, using a 50 penetration grade bitumen and cellulose fibres. The two asphalt mixtures were selected to represent a typical UK base and wearing course (surfacing) material. The primary and secondary aggregates used in various combinations to produce the above asphalt mixtures are: Gritstone aggregate (Bayston Hill) with a SG of 2.76; Limestone aggregate (Ballidon) with a SG of 2.7; Limestone filler (Ballidon) with a SG of 2.7; Steel slag (Llanwern) with a SG range of 3.0 to 3.27 ; Blast furnace slag (Port Talbot) with a SG range of 2.36 to 2.47; and Glass cullet with a SG of 2.5. The six primary and secondary aggregates and fillers, together with the two asphalt mixture gradations and one binder type, were used to produce six asphalt mixture combinations (two control and four secondary aggregate mixtures). The stiffness modulus of the primary and secondary mixtures was measured using the Indirect Tensile Stiffness Modulus (ITSM) test according to British Standard DD213. The permanent deformation resistance of the different asphalt mixtures was determined by means of the Confined Repeated Load Axial Test (CRLAT) using a direct uniaxial compression configuration according to British Standards DD185. The fatigue resistance of the asphalt mixtures was determined by means of the Indirect Tensile Fatigue Test (ITFT) with an experimental arrangement similar to that used for the ITSM but under repeated loading and with slight modifications to the testing modulus crosshead. They concluded that the overall effect of replacing the primary aggregate with glass cullet was a slight reduction in asphalt mixture stiffness relative to the control limestone mixture. They found that though the moisture susceptibility of the glass aggregate mixtures was greater than the control mixture, a situation they adduced to the smooth surface texture of the glass, the retained stiffness values after longterm moisture conditioning were still considered acceptable. The use of an anti-stripping agent did improve the material's resistance to moisture damage. In terms of the materials' ageing resistance, the addition of glass cullet significantly reduced the ageing susceptibility of the modified mixtures. The permanent deformation performance of the glass cullet mixtures was found to be inferior to that of the control mixture. The greater rutting susceptibility of the glass aggregate mixtures was attributed to the smooth surface texture of the glass aggregate resulting in less aggregate interlock and surface friction which was not improved by the addition of an anti-stripping agent. However, they emphasized that the rutting performance could still be considered to be satisfactory as the final permanent strains were still below an acceptable limit. The fatigue performance of the limestone and glass aggregate mixture was found to be comparable to that of the control mixture. Androjić and Kaluđer [16] did a thorough review on the use of waste materials in the production of asphalt mixes. They analysed research conducted with regard to the use of various waste materials as replacement for traditional fillers in asphalt mixes. They concluded from the research reviewed that waste glass, cement industry waste materials, concrete, bricks, ceramics, fly ash and other raw materials could be used as replacement for standard filler in bituminous mixes. They also mentioned that the use of various nonconventional fillers should be studied through construction of trial sections in order to enable better analysis of behavior of such asphalt layers in actual use. They noted that the use of various waste fillers in the production of asphalt mixes had led to the fall in the price of mixes resulting in a more acceptable influence of asphalt industry on natural environment.

Su and Chen [17] carried out laboratory/field test on the use of glass in asphalt to confront the waste problem facing Taiwan as it produces nearly 5 million tons of waste each year, out of which $10 \%$ is of glass materials. They considered 85/100 asphalt, Type II modified asphalt, and treated glass waste. The study involved four glass contents: $0 \%, 5 \%$, $10 \%$, and $15 \%$, by the total aggregate weight. They produced samples having $10 \mathrm{~cm}$ diameter by 6.35 $\mathrm{cm}$ thick and determined Marshall stability value, dry/wet moisture damage, skid resistance, light reflection, water permeability, and compaction in 
accordance with the ASTM and AASHTO procedures. They concluded that glass waste was a viable material for asphalt concrete and offered profound engineering and economic advantages. Arbani [18] evaluates the behaviour of hot mix asphalt (HMA) with varying admixture contents and gradation of the aggregates at different temperature conditions. It was found that the addition of glass cullet led to an increase in the stiffness of asphalt mixture because the glass particles with crushed structure and high angularity increased the internal friction of the asphalt mixture. Furthermore, the study showed that the sensitivity of the asphalt with glass cullet to temperature was lower than the conventional HMA. Generally, it was concluded that there was an improvement in the dynamic behaviour of the glass-asphalt mixture in comparison with conventional HMA mixtures. Arbani et al. [19] investigated the introduction of waste glass into asphalt to address fatigue failure. The study involved modelling of the fatigue behavior of glasphalt under dynamic loading and comparison with thesuggested behavior of hot mix asphalt (HMA). They concluded that glasphalt concrete mixtures had longer fatigue life than HMA. Generally, the literature review indicates that glass can be used successfully as an aggregate and filler in asphalt concrete (surfacing) and base layers of flexible pavements, with the authors suggesting different sizes of the waste glass. Most studies were carried out on its use as aggregate rather than as filler. This study considers the use of waste glass as filler in the asphalt concrete and the objective is to determine and compare the Marshall properties of the conventional asphalt concrete used in Nigeria with asphalt concrete incorporating waste glass as filler.

\section{Materials and methods}

\subsection{Materials}

The materials used for this study are natural aggregates, bitumen, and waste glass. The aggregates used for this study are $20 \mathrm{~mm}, 12.5 \mathrm{~mm}$, $9.5 \mathrm{~mm}$ single-sized aggregates, river sand and stone dust. The single-sized and the stone dust aggregates are granitic in nature and they were sourced from a quarry. They met the specifications required of aggregates to be used as asphaltic concrete base-course and wearing course, that is, aggregate crushing value and flakiness index not exceeding 30 and 35, respectively. The stone dust was collected from the yard of an asphalt producing company. The samples of the aggregates are shown in Fig. 1. The aggregates gradations were determined in accordance with the British Standards [20]. A 60/70 penetration grade commonly used for pavement in Nigeria was used and a penetration test was conducted on the bitumen sample. The penetration test was carried out in accordance with BS EN 1426:2007 [21]. The waste glass bottles were obtained from a brewery. The bottles were cleaned and then crushed manually to powder. The sample is shown in Fig. 2. The aggregates and the bitumen were used in producing the asphalt concrete in accordance with the Federal Government of Nigeria general specifications for roads for binder course [22].

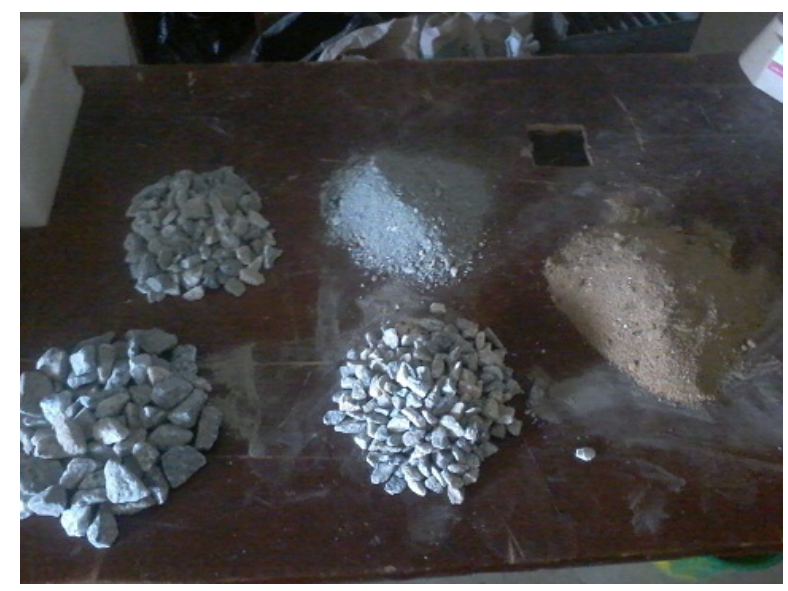

Figure 1. Samples of the aggregates

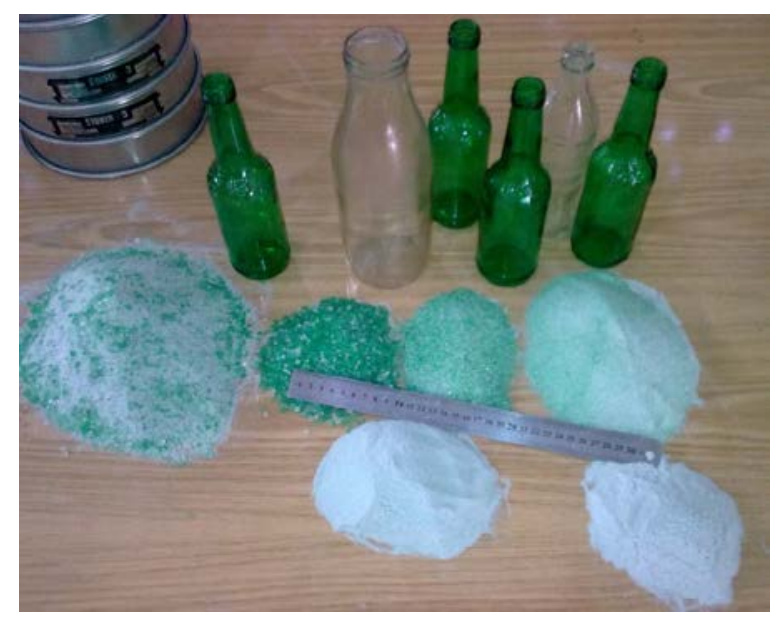

Figure 2. Sample of the waste glass

The conventional asphalt concrete base course is normally produced from blend of aggregates falling 
within the envelope shown in Table 1 with bitumen of $80-100$ pen or $60-70$ pen [22]. The penetration test results are shown in Table 2 . This confirms the grade of the bitumen used in the study. The particle size distribution curves of the aggregates and the blend of aggregates are shown in Fig. 3. The blend of aggregates falls within the envelope specified for binder course in the General Specification for Roads and Bridges [22].

Table 1. Grading envelope for binder course

\begin{tabular}{|c|c|}
\hline Sieve Size (mm) & \% By Weight Passing \\
\hline 31.8 & 100 \\
\hline 25 & $90-100$ \\
\hline 19 & $70-90$ \\
\hline 12.5 & $55-80$ \\
\hline 9.5 & $47-70$ \\
\hline 6.4 & $40-60$ \\
\hline 2.8 & $27-45$ \\
\hline 1.25 & $20-34$ \\
\hline 0.6 & $14-27$ \\
\hline 0.3 & $8-20$ \\
\hline 0.15 & $5-15$ \\
\hline 0.075 & $2-7$ \\
\hline $\begin{array}{c}\text { Bitumen Content \% by } \\
\text { weight of aggregate }\end{array}$ & $4.5-6.5$ \\
\hline
\end{tabular}

Table 2. Penetration test results

\begin{tabular}{lcll}
\hline Sample & 1 & 2 & 3 \\
\hline Test temperature $\left({ }^{\circ} \mathrm{C}\right)$ & 25 & 25 & 24 \\
Penetration $(\mathrm{dmm})$ & 65 & 67 & 57 \\
Average & & 63 & \\
\hline
\end{tabular}

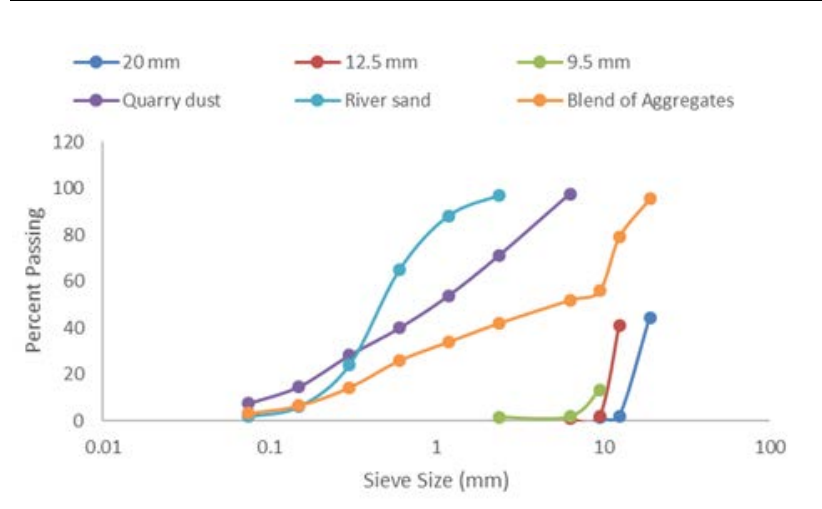

Figure 3. Particle size distribution curves of the aggregates and blend of aggregates for the asphalt concrete

\subsection{Methods}

The methods adopted involve preparation of the asphalt concrete in accordance with the Federal Government of Nigeria general specifications for roads for binder course [22]. The Marshall test was conducted on the blend of aggregates without waste glass and the optimum binder content was determined. Then, the asphalt mixture with the optimum binder content was prepared with $8 \%$, $10 \%, 12 \%, 14 \%, 16 \%, 18 \%$ and $20 \%$ waste glass of the total mix. The samples with the waste glass were then subjected to the Marshall test. The procedures are highlighted in the following sections.

\subsubsection{Specimen preparation}

The asphalt mix requires the combination of two or more aggregates having different gradation to produce an aggregate blend that meets gradation specification for a particular asphalt mix. The aggregates, that is, $20 \mathrm{~mm}, 12.5 \mathrm{~mm}, 9.5 \mathrm{~mm}$, quarry dust, river side were blended in order to get the proper gradation within the allowable limit according to General Specifications for Roads and Bridges [22]. The heated aggregates and binder were mixed in accordance with BS EN 1269735:2004 [23]. The mix composition used for the study is shown in Table 3 .

To prepare the specimen, $1200 \mathrm{~g}$ of aggregates were weighed using the proportion shown in Table 3 . The aggregates were heated to a temperature of $150{ }^{\circ} \mathrm{C}$ before mixing with bitumen. A crater was formed in the aggregate and the $60 / 70$ penetration grade bitumen heated to $150{ }^{\circ} \mathrm{C}$ was added. The aggregates and the bitumen were mixed until all the aggregates were properly coated. Filter paper was placed in the bottom of a thoroughly cleaned mould, heated to $150{ }^{\circ} \mathrm{C}$ and the mixture placed in the mould was spread with a heated spatula around the perimeter. The collar was removed, and the surface of the mix was smoothened with a trowel to a slightly rounded shape. Temperature of the mixture was maintained at $140{ }^{\circ} \mathrm{C}$ immediately prior to compaction. The collar was replaced, and the mould assembly was placed on the compaction pedestal in the mould holder, and the top of the specimen was given 75 blows. The baseplate and the collar were removed, and the sample was inverted and the mould reassembled. The inverted face was also given 75 blows. After compaction, the base plate was removed and the mould containing the specimen was immersed in cool water for 2 minutes. 
The specimen was removed from the mould by means of sample extractor and a suitable jack and frame arrangement (see Fig. 4). The specimen was placed on a smooth, flat surface and allowed to cool at room temperature.

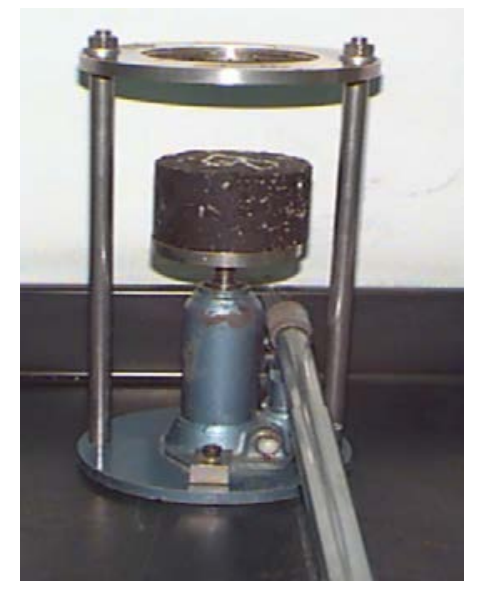

Figure 4. Marshall Specimen Extractor

Table 3. Mix composition

\begin{tabular}{cc}
\hline Aggregates & Percent of total mix \\
\hline $20 \mathrm{~mm}$ & 8.0 \\
$12.5 \mathrm{~mm}$ & 22.0 \\
$9.5 \mathrm{~mm}$ & 17.0 \\
Quarry dust & 38.0 \\
River sand & 15.0 \\
\hline Total & 100 \\
\hline
\end{tabular}

\subsubsection{Test procedure}

The Marshall test was conducted on the asphalt concrete samples without glass using the Marshall equipment shown in Fig. 5. Samples with five different bitumen percentages (4.0, 4.5, 5.0, 5.5 and $6.0 \%)$ were examined to determine the optimum bitumen content. The asphalt concrete samples incorporating $8,10,12,14,16,18$ and $20 \%$ glass by weight of the total aggregate using the optimum bitumen content were subjected to the Marshall test. The density was determined by weighing the samples in air and in clean water at room temperature. The difference between the two weights in grams was used to determine the volume. Also, the stability and flow were determined. This was done by bringing the samples to test temperature by immersing in water bath for 20 to 40 minutes. The guide rods and the inside surfaces of the test heads were thoroughly cleaned. The guide rod was lubricated so that the upper test head could slide freely over them.

The specimen from the water bath was placed in the lower segment of the breaking head. The upper segment of the breaking head was placed on the specimen and the complete assembly was placed in position on the testing machine. The flowmeter was placed over the guide rods and the sleeve was held firmly against the upper segment of the breaking head while the load was applied. The flowmeter was adjusted to zero prior to the start of the test. The load was applied to the specimen at the rate of 50 mm per minute until the maximum load was reached and the load began to decrease. The maximum load was recorded, and the flowmeter was removed from its position over the guide rod the instant the load began to decrease. The flow value was read and recorded.

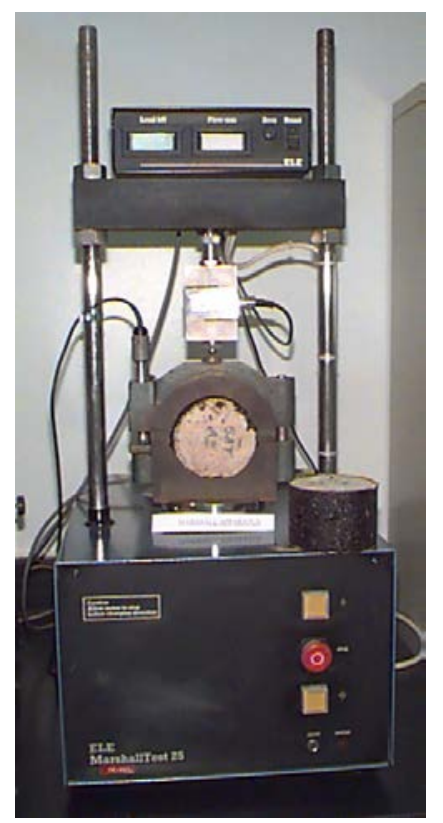

Figure 5. Marshall stability and flow test equipment

\section{Results and discussion}

The results of the stability of the asphalt concrete with and without waste glass is shown in Fig. 6. The results show the stability of asphalt concrete with waste glass increases as the glass content increases up till $18 \%$ and decreases with addition of $20 \%$ glass waste. Generally, the results show that the stability of the asphalt concrete incorporating waste glass is lower than the conventional asphalt concrete. The decrease in stability was caused by the fact that the waste glass was added as percentage of 
the total mix. As stated earlier, the waste glass bottles were crushed and ground to powder and used in form of a filler. However, the stability values were all greater than $3.5 \mathrm{kN}$, which is the minimum value specified in the General Specifications, Roads and Bridges [22], except when $20 \%$ waste glass was introduced. The flow of the asphalt concrete with and without the waste glass is shown in Fig. 7. The results show that the flow of asphalt concrete with waste glass reduces to $8 \%$, while it increases with the increasing glass content from 10 to $20 \%$. The values for $8 \%$ to $14 \%$ are within the range of $2 \mathrm{~mm}$ - $6 \mathrm{~mm}$ specified in the General Specifications, Roads and Bridges [22] for binder course. The high flow values recorded for the samples with the waste glass content of $16 \%, 18 \%$ and $20 \%$ indicate plastic mix. This could be attributed to the high content of the filler.

The bulk density of the asphalt concrete with waste glass is shown in Fig. 8. It indicates that the bulk density of the asphalt mix increases as the glass content increases up to $18 \%$ and reduces with addition of $20 \%$ glass. The reduction of the density at $20 \%$ implies that too much of the waste glass results into a tender mix, making it difficult to place and compact. The graph of voids in total mix of the asphalt concrete with and without the waste glass is shown in Fig 9. The results show that air voids decrease with increasing glass content up to $18 \%$ and increase with $20 \%$ glass content. The decrease in the air voids is attributed to the increased fine content of the mixture. Also, the reduction in the air voids with increasing glass contents implies increased stability and improved durability (see Fig. 6 ). The high air voids recorded with the addition of $20 \%$ waste glass is because of the insufficient bitumen to fill the voids. The air voids values at $8 \%$ - $16 \%$ waste glass content are within the range specified in the General Specifications, Roads and Bridges for binder course [22].

The graph of voids in mineral aggregates of the asphalt concrete with and without waste glass is shown in Fig 10. The voids in mineral aggregates decrease with the increasing glass content up till $18 \%$. The VMA of the asphalt concrete with waste glass was greater than the one without the waste glass at $8 \%$ and $20 \%$. The reduction in the VMA follows the same trend as the air voids. The voids filled with bitumen (VFB) against the percent waste glass in the total mix is shown in Fig. 11. This shows that the VFB increases with increasing waste glass up to $18 \%$ and reduces at $20 \%$. This is expected as the VFB is calculated as the percentage of the VMA, which reduces with increasing waste glass (see Fig. 10). The increase in the VFB with increasing waste glass implies improved durability of the asphalt concrete. The VFB at $12 \%$ and $14 \%$ waste glass content are in the range of $65 \%$ to $72 \%$ specified in the General Specifications, Roads and Bridges for base-course [22].

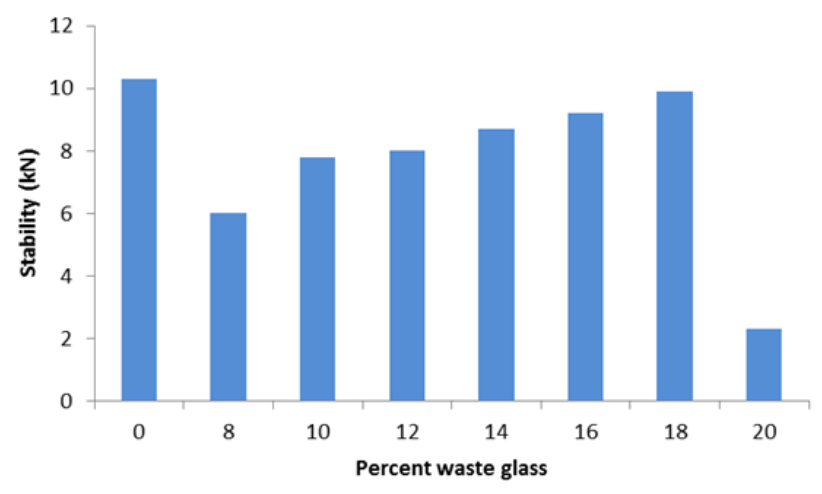

Figure 6. Stability of the asphalt concrete with and without waste glass

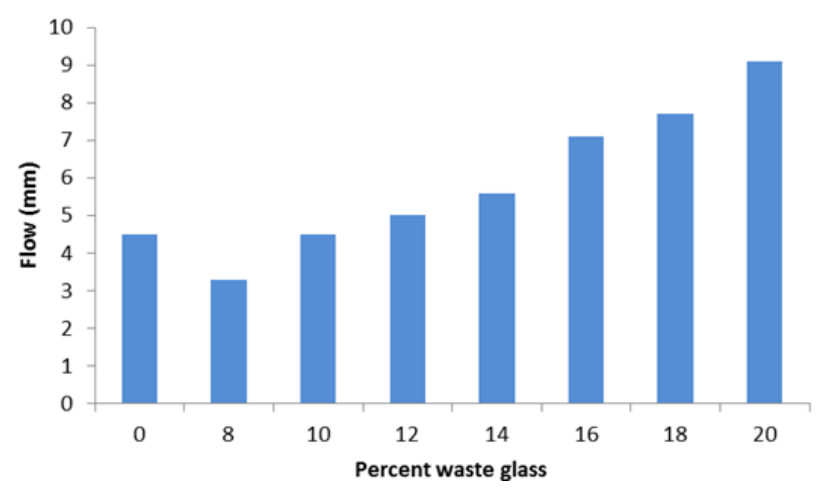

Figure 7. Flow of the asphalt concrete with and without waste glass

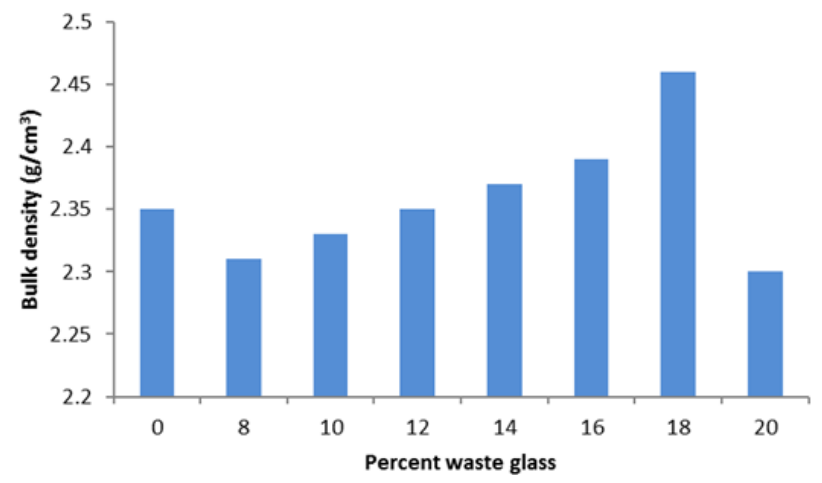

Figure 8. Bulk Density of the asphalt concrete with and without waste glass 


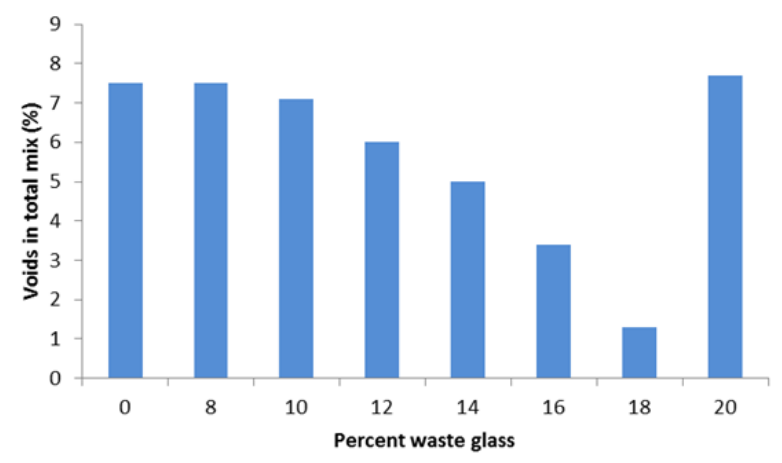

Figure 9. Voids in the total mix of the asphalt concrete with and without waste glass

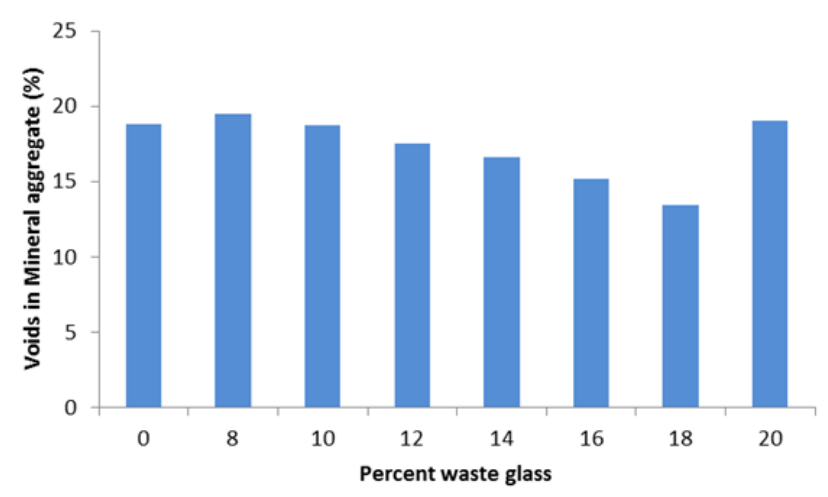

Figure 10. Voids in mineral aggregates for the asphalt concrete with and without waste glass

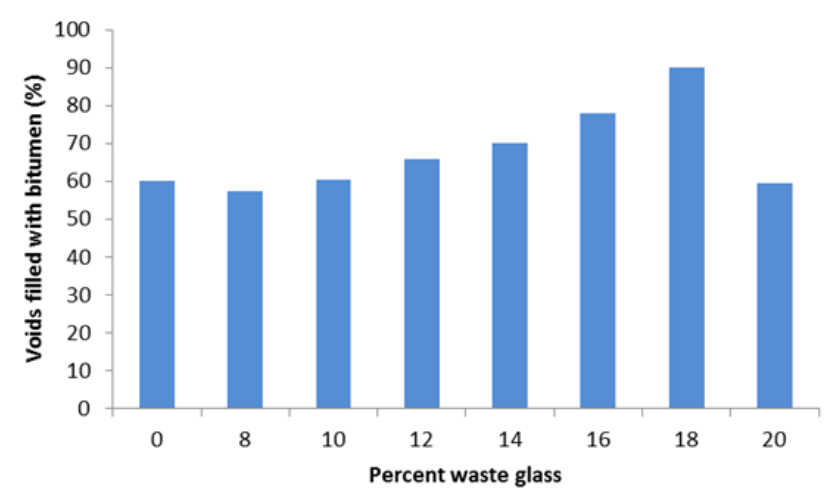

Figure 11. Voids filled with bitumen for the asphalt concrete with and without waste glass

\section{Conclusion}

The objective of this study is to determine the effect of using waste glass on the Marshall properties of a typical asphalt binder course used in Nigeria. The Marshall test results show that the stability increases when increasing glass filler up to $18 \%$, which implies improved resistance to fatigue, although lower than the one without the waste glass. Also, the flow reduces waste glass content to $8 \%$ and thereafter increases with increasing glass filler, which implies that the resistance to permanent deformation did not improve with waste glass content greater than $8 \%$. The results show that the bulk density of the asphalt concrete with waste glass increases, therefore enhancing its properties. It was also found that the air voids reduce with increasing glass filler, while the voids filled with bitumen increase. These imply improved stability and durability of the asphalt concrete. Generally, the study shows that waste glass could be introduced into asphalt concrete. The results indicate that further studies are required on the glass gradation, the percentage required in the mix, the replacement of aggregates certain sizes or filler completely with the waste glass. The introduction of waste glass in the asphalt concrete is environmentally friendly and it will aid the sustainable management of waste glass.

\section{References}

[1] Kandhal, P. S.: Waste Materials in Hot Mix Asphalt - An Overview, National Center for Asphalt Technology, NCAT Report No. 92-6m 1992.

[2] Warren, J.: The Use of Waste Materials in Hot Mix Asphalt, NAPA Special Report 152., 1991.

[3] Andela, C., Sorge, E.V.: Handbook of Alternative Uses for Recycled Glass

[4] Larsen, D. A.: Feasibility of Utilizing Waste Glass in Pavements, Connecticut Department of Transportation, Report No. 343-21-89-6., 1989.

[5] Abu Salem, Z. T., Khedawi, T. S., Baker, M. B., Abendeh, R.: Effect of Waste Glass on Properties of Asphalt Concrete Mixtures, Jordan Journal of Civil Engineering, 11 (2017), $1,117-131$.

[6] Halstead, W.J.: Use of Waste Glass in Highway Construction, Virginia Transportation Research Council, VTRC 93-TAR2, 1993.

[7] Issa, Y.: Effect of Adding Crushed Glass to Asphalt Mix, Archives of Civil Engineering, 62 (2016), 2, 35-44.

[8] Arnold, G., Werkmeister, S., Alabaster, D.: The Effect of Adding Recycled Glass on the Performance of Basecourse Aggregate, New Zealand Transport Agency, NZ Transport Agency Research Report 351, 2008. 
[9] Swearingen, D. L., Jackson, N. C., Anderson, K. W.: Use of Recycled Materials in Highway Construction, Washington Department of Transportation, WA-RD-252.1, 1992.

[10] Anochie-Boateng, J. K., George, T. B.: Use of Waste Crushed Glass for the Production of Hot-Mix Asphalt, Sustainable Construction Materials and Technologies, SCMT4 Las Vegas, USA, August 7-11, 2016.

[11] Jony, H. H., Al-Rubaie, M. F., Jahad, I. Y.: The Effect of Using Glass Powder Filler on Hot Asphalt Concrete Mixtures Properties, Eng. \& Tech. Journal, 29 (2011), 1, 44-57.

[12] Dalloul, K. N.: Study of the Effect of Crushed Waste Glass as Coarse Sand and Filler in the Asphalt Binder Course, Master Thesis in Infrastructure Engineering, The Islamic University of Gaza, 2013.

[13] Sadeghnejad, M., Arabani, M., Taghipoor, M.: Predicting the impact of temperature and stress on the glasphalt mixtures' rutting behavior, Int. J. Pavement Res. Technol., 2017.

[14] Al-Saeedi, B. J. K, Al-Jameel, H. A. E.: Sustainable Performance of Iraqi Asphalt Base Course Using Recycled Glass as Aggregate Replacement, Journal of University of Babylon, Engineering Sciences, 26 (2018), 5

[15] Airey, G. D., Collop, A. C., Thom, N. H., Mechanical Performance of Asphalt Mixtures Incorporating Slag and Glass Secondary Aggregates, Proceedings of the 8th Conference on Asphalt Pavements for Southern Africa
(CAPSA'04) 12 - 16 September, ISBN Number: 1-920-01718-6, 2004.

[16] Androjić, I., Kaluđer, G.: Influence of Recycled Filler on Asphalt Mix Properties, Građevinar, 69 (2017), 3, 207-214.

[17] Su, N., Chen, J. S.: Engineering properties of asphalt concrete made with recycled glass, Resources Conservation and Recycling, 35 (2002), 4, 259-274.

[18] Arabani, M.: Effect of Glass Cullet on the Improvement of the Dynamic Behaviour of Asphalt Concrete, Construction and Building Materials, 25 (2011),3, 1181-1185.

[19] Arbani, M., Mirabdolazimi, S. M., Ferdowsi, B.: Modeling the Fatigue Behaviors of Glasphalt Mixtures, Sci Iran, 19, 3, 341-345.

[20] BSI: Tests for Geometrical Properties of Aggregates- Determination of Particle Size Distribution (Sieving Method), British Standard Institution, London, UK (BS EN 933-1:1997), 1997.

[21] BSI: Bitumen and Bituminous BindersDetermination of Needle Penetration. British Standard Institution, London, UK (BS EN 1426:2007, BS 2000-49:2007), 2007.

[22] FGN: Government of the Federal Republic of Nigeria, General Specification (Roads and Bridges), Volume II, 1997.

[23] BSI: Bituminous Mixtures-Test Method for Hot Mix Asphalt: Laboratory Mixing, British Standard Institution, London, UK (BS EN 12697-35:2004), 2004. 